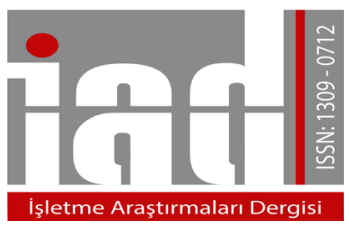

\author{
İşletme Araştırmaları Dergisi \\ Journal of Business Research-Turk \\ 10/4 (2018) 136-147
}

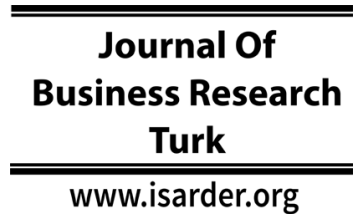

$\underline{\text { Research Article }}$

\title{
Time Varying Causality Between Cost and Price: An Empirical Analysis on Dry Bulk Shipping Market
}

\author{
Abdullah AÇIK \\ Dokuz Eylül University \\ Maritime Faculty, Tinaztepe Campus \\ 35160 Buca- Izmir, Turkey. \\ orcid.org/0000-0003-4542-9831 \\ abdullah.acik@deu.edu.tr
}

\author{
İlke Sezin AYAZ \\ Dokuz Eylül University \\ Maritime Faculty, Tinaztepe Campus \\ 35160 Buca- Izmir, Turkey. \\ orcid.org/0000-0002-7053-3940 \\ ilkesezinayaz@gmail.com
}

\begin{abstract}
Fluctuations of freight income and volatility of bunker prices are together having an important impact on shipping profits because oil, which is the main source of bunker fuel, constitutes substantial operational expense to shipping firms, and it accounts for $34-44 \%$ of the whole operation costs. However, as the freight rates in live market conditions are determined by demand, the determinative characteristics of bunker price loses its importance. In this respect, it is not wrong to say that the relationship between bunker prices and freight rates changes according to time. Therefore, with the aim of filling the gap in the related literature, the relationship between these two variables is examined by time-variance causality analysis. The data set used in the study consists of 318 observations on a monthly basis covering the period January 1992 to June 2018. As a result of the study 24 causality periods with lengths ranging from 1 month to 13 months are determined. Also, it is spotted that they are intersected with BDI in the declining regions of the index in general and this result confirms that the causality between the freight rates and the bunker prices is realized in the stagnant market conditions.
\end{abstract}

Keywords: Bunker Price, Freight Rates, Dry Bulk Shipping, Time Varying Causality

Received 17 September 2018; Received in revised from 9 November 2018; Accepted 15 November 2018

\section{Introduction}

Maritime transportation which is the subsystem of global transportation and logistics network, one of the most cost effective solution for move goods and raw materials, generates over $90 \%$ of the world trade (IMO, 2015). Also, maritime transportation increases effective domestic demand and employment level, and thus positively effects country's economic progress (Shi and Li, 2017). Characteristics of

\section{Suggested Citation:}

Açık, A., Ayaz, I.S. (2018). Time Varying Causality Between Cost and Price: An Empirical Analysis on Dry Bulk Shipping Market, Journal of Business Research-Turk, 10 (4), 136-147. 
maritime transportation include high volatility, demand uncertainty, strong cyclicality and seasonality (Stopford, 2009). Shipowners and charterers are facing significant financial risks and uncertainties for example freight rates, oil prices, foreign exchange rates, interest rates and more (Kavussanos and Visvikis, 2006). Especially, fluctuations of freight income and volatility of oil prices are together having an important impact on shipping profits (El-Masry, Olugbode, and Pointon, 2010).

The ship owner, who is involved in maritime transport activities, affords to bear a lot of costs. These costs are classified under 5 main headings by Stopford (2009: 221); (i) costs incurred by the ship's daily operations such as crew, stores and maintenance; (ii) periodic costs such as dry-docking for major repairs in particular inspection processes; (iii) special voyage costs on a journey such as bunker costs, port charges and canal dues; (iv) costs associated with ship financing such as interest and capital payments; and finally, (v) cargo handling costs, such as loading, stowing and discharging. Oil, which is the main source of bunker fuel, constitutes substantial operational cost to maritime transport firms, and it forms part of $34-44 \%$ of the whole operational expenses (Notteboom and Vernimmen, 2009). Moreover, according to maritime industry's operations, actions of freight revenue is quite consistent with the increase of bunker costs and its price constantly fluctuates due to market forces and the cost of oil (Yin, Luo and Fan, 2017). Because of this relation, fluctuations of shipping freight rates and the oil prices are highly important for trading and risk management in the shipping industry (Sun et al., 2018, p. 175). of approximately $80 \%$.

During the 2008 financial crisis, freight rates and oil prices respectively suffered a sharp decline about $90 \%$ and nearly $80 \%$. The freight rates were dominated by a great uncertainty, and so the maritime operators and investors faced large exposures (Notteboom and Vernimmen, 2009). Also, according to RMT (Review of Maritime Transport 2017), the growth rate of world seaborne trade volume exhibited a sharp slowdown after the financial crisis, from $7.01 \%$ in 2010 to $2.63 \%$ in 2016 . The daily earnings of dry bulk carriers fell to $\$ 7123$ in 2015, the lowest level since 1999, which is even worse than the market guessed. Due to the decreasing demand and excess transport capacity in the market, the freight rates have not been able to meet the daily operational costs of dry bulk carriers and the losses of many bulk carriers have increased in 2016 (Clarksons Research, 2016). Thanks to the decline in oil prices and small growth on the demand side, the tanker market was relatively better by 2015 . However, due to the increase in the carrying capacity in the market and the decline in demand for oil, the freight rates in the tanker market also exhibited a slowdown in 2016. In the container market, the annual demand growth rate in the container freight market declined from $12.8 \%$ in 2010 to $3.0 \%$ in 2016 while the container supply capacity went up by $1 \%$, compared with $8 \%$ in 2015 . For example, the average freight price of a 20 -ft equivalent container in the Far East-Northern Europe trade route fell to $\$ 683$ in 2016. This price is nearly $41.17 \%$ lower than the 2014 average price and nearly $61.82 \%$ lower than the 2010 average price (Review of Maritime Transport, 2017). When we look at oil prices, 
oil prices were quite stable until 2007, however then there was a sharp rise in prices as the general economy evolved. After the second half of 2014, oil prices dropped sharply and fell by about $50 \%$. In addition to demand for oil, political strategies have also had a great impact on these volatilities in the price of the crude oil (Yao, 2017; Zhan, 2017).

As it can be seen all these developments, shipping freights and oil prices are both derived from the changeable world economy and trade and consisting inseparable relations with each other. Therefore, it is of great importance to study the connection between shipping freight rates and oil prices because of high risks, cumbersome costs and intense variations. This relationship is important since the cost of fuel is directly affected by the oil price and this cost item constitutes a large part of the operating expenses of the vessels. However, the effect of bunker prices on freight rates is limited in periods when the economy is alive and there is no supply surplus in the fleet. Because prices are shaped according to demand in such periods. But, in the periods when the economic recovery has come to an end or the excess supply in the fleet has occurred, the freight rates may fall to the level of operational expenses. Even in these periods, the old and obsolete ships with very large operational costs are scraped and disqualified from the race. In this context, it is inevitable to have periodic causality between freight rates and fuel prices.

Many methods are used in causality analysis and they have evolved over time. Nonlinear and time-varying causality analyzes are used instead of methods such as standard linear Granger causality analysis, which makes a single causality analysis based on the whole sample. Because the causality between the two variables may change over time, namely a variable may Granger cause the other in some periods but not in other periods. So, a rolling-window sub-samples Granger causality test based on the modified bootstrap estimation is used in this study. Unlike the full-sample standard Granger causality test, this method can spot structural shifts, therefore the evaluation of the causal relationship can be traced. Therefore this approach identifies possible timevarying causalities between the series. In this framework, this study contributes to existing literature by taking into account time variations in the causal links between bunker price and freight rates in the dry bulk market. The data set used in the study consists of 318 observations on a monthly basis covering the period January 1992 to June 2018. The causal relationship is tested unidirectional and the null hypothesis is that the bunker price does not Granger cause freight rates. The hypothesis is tested at the 10 $\%$ significance level and the $\mathrm{p}$ values change over the whole sample. As a result of the study 24 causality periods with lengths ranging from 1 to 13 are determined. Also it is seen that some causality periods are interrupted by a few observations. It is thought to be more rational to examine these interrupted periods together as a single period. The new longest period with these mergers becomes the 24-month period covering December 2010 and January 2013. After this determination, the results and the flow of the BDI variable are examined together to see relationship more clear. It is spotted that they are intersected in the declining regions of the BDI in general. Because when the 
recession begins on the market and freight rates begin to fall, shipowners or charterers adjust their freight rates based on their fuel costs. This cost constitutes their biggest cost item and it is virtually impossible to make a proposal under this price. However extreme freight rates are generated well above this cost level during periods when the market is alive, since the price of the fuel in live markets loses its importance.

The remainder of the study is organized as follows; the relevant literature is examined in the second section; the method used is introduced in the third section; the results obtained from the analyzes are presented in the fourth section; and the conclusons are made in the final section.

\section{Literature Review}

When the studies in the related literature are examined, it is seen that there is no study investigating the time-varying causal relationship between bunker price and freight rate. The number of different types of studies examining this relationship is also found to be low. Poulakidas and Joutz (2009) investigates the effects of oil price spikes on the tanker freight rates. They have investigated the lead-lag relationship between crude oil prices, crude oil inventories and tanker rates. They have implemented cointegration and Granger causality analysis, the results have revealed that there are significant leadlag relationships between the variables. In another study related to the crude oil price and maritime freight markets, the causal relationship between crude oil price and dry bulk freight rates have been investigated by Shen and Chou (2015). They have used West Texas Intermediate (WTI) oil and several Baltic Exchange indices as representations of the relations. According to the results of the cointegration and Granger causality analysis, there is significant cointegration between crude oil price and freight market indices, and crude oil price is the Granger cause of the all Baltic indices. However, the opinion that fuel prices are always the cause of the freight rates is somewhat lacking in our opinion. At this point, the factors affecting the freight rates should be evaluated.

Shipping freight rates are generally influenced by both internal and external factors. The shipping demand is a derived demand and the world economy has the most important influence on the shipping demand because it creates the demand for maritime transport by importing raw materials for production or trade of ready products (Jugovic et al., 2015, p. 25). The relationship between time charter rates and a number of variables have benn examined by Zanettos (1966). The variables that he has chosen are important to prove the diversity of factors affecting the freight rates, and the selected variables are London Interbank Offered Rate (LIBOR), the oil price, the Air transportation index, laid-up tonnage, scrapped tonnage and operating expenses. The macroeconomic and internal variables that affect freight rates have been investigated by Strandenes (1984), and after that Beenstock and Vergottis (1989, 1993). They have found that the freight rates are affected by several macroeconomic variables such as the growth of industrial production, commodities trade, oil prices, world economic activity. 
Also the rates are affected by some internal factors such as orders for newbuilding ships, deliveries of newly build ships, and demolition activities. In addition, factors affecting stock values as a reflection of freight revenues have also been examined, and these factors may also affect freight rates. The effect of several macroeconomic variables on stock values of various shipping companies have been examined by Grammenos and Arkoulis (2002). The macro variables they have used are industrial production level, exchange rates, inflation, oil prices, and laid up tonnage.

As can be seen from these studies, many different factors affecting the freight rates have been identified in many studies. Bunker price (oil price) has also been used in these studies. However, it is emphasized that many other factors are effective in addition to this factor. Therefore, the relationship between bunker price and freight rate is not a continuous relationship. In times of economic recovery, the price of bunker loses its importance since the freight rates are determined by demand. In the periods when the freight rates hit rock bottom, the owners can give very little price over the operating costs, and the bunker costs constitute a large part of these costs. Therefore, a causal relationship begins between them.

In this context, this study aims to examine the causal relationship between bunker prices and freight rates in a time-varying form and to reveal the relationship between two variables in a more transparent way. In the next section, the method used in the study is introduced.

\section{Methodology}

There are many different methods in the analysis of the causal relationships between variables. The most common one is the Granger (1969) causality analysis, and most of the other analyzes are derived from this method. Actually, the logic in this analysis is simple; when examining the causality analysis between two variables, if the past values of the first variable succeed in predicting the current value of the second variable, then the first variable is said to be a Granger cause of the second variable. The causality is tested as whether the lagged values corresponding to past of the first variable are significant or not (Balcilar and Ozdemir, 2013b). The null hypothesis of this test implies Granger non-causality from first to second variable, which indicates that information on the first variable does not improve the prediction of the second variable (Inglesi-Lotz et al., 2014).

Recent developments have been made in this method with studies on causality analysis with respect to its inadequacies. For instance, all types of standard Granger causality tests make causality analyzes based on the entire sample. However, the causality between the two variables may change over time in such a way that a variable may Granger cause the other in some periods but not in other periods (Balcilar and Ozdemir, 2013a). The causal relationship between variables may be time varying and may not be observed in the every point in the entire sample (Balcilar and Ozdemir, 2013b). Also there is no strong evidences about linearity of the economic relationships 
(Bampinas and Panagiotidis, 2015) since economic and financial series are highly volatile and often exposed to economic crisis (Bildirici and Turkmen, 2015). But linear causality approach makes a strong assumptions about fixity of the parameters over time (Inglesi-Lotz et al., 2014), so it fails to spot nonlinear causal relations (Bal and Rath, 2015).

It is complained about inconsistent outcomes in studies that examine causality between two variables since the structural changes and breaks may occur in the sample when the whole sample is considered. Though, the bootstrap rolling-window approach allows to detect possible time-varying causalities based on sub-sample data instead of presuming a constant causality in every time period (Li et al., 2016). Also this method allows to capture structural shifts and allows to see evaluation of causal relationship between sub-periods (Inglesi-Lotz et al., 2014). The one of the important points of this method is how large the window should be. However, Balcilar et al. 2010 have indicated that there is no consistent criterion for selecting the optimal window size in the rolling window estimation. They have stated that there may be less representativeness of parameters in the larger window size. The degree of representativeness increases in smaller window sizes, but this may lead to big standard errors which cause biased parameters. So a balance between accuracy and representativeness should be established considering these two aspects.

In this study, time-varying causality analysis between bunker price and freight rate is performed by the bootstrapped Granger non-causality tests with fixed size rolling-window. Two important reasons for using a rolling window are; (i) the rolling window is in accordance with the fact that the causal relationship between variables changes over time; (ii) the rolling window estimation can spot instability between different sub-sample groups due to the structural changes (Li et al., 2016). Therefore, this type of analysis is considered the most appropriate method for our study, as fuel prices in live market conditions cannot be determinant for freight rates. But in poor market conditions the ship operators have to base their freight rates on their fuel costs and cannot offer a lower price than that. In the next section, findings and results obtained using this methodology are presented.

\section{Findings and Results}

The BDI and Bunker variables which are desired to be analyzed in the study are shown in Figure 1. A positive correlation between the variables can be observed in general but a perfect relationship can not be traced. Although the fuel price is the most important cost item in the transportation costs, this cost can not always be taken as basis for the determination of the freight rates. There are many factors that affect freight rates in the maritime market apart from the relationship that should be linear in theory, and these factors lead to a non-linear relationship which changes over time. Therefore, in this study, an analysis of time varying causality form fuel prices to freight rates is studied. 


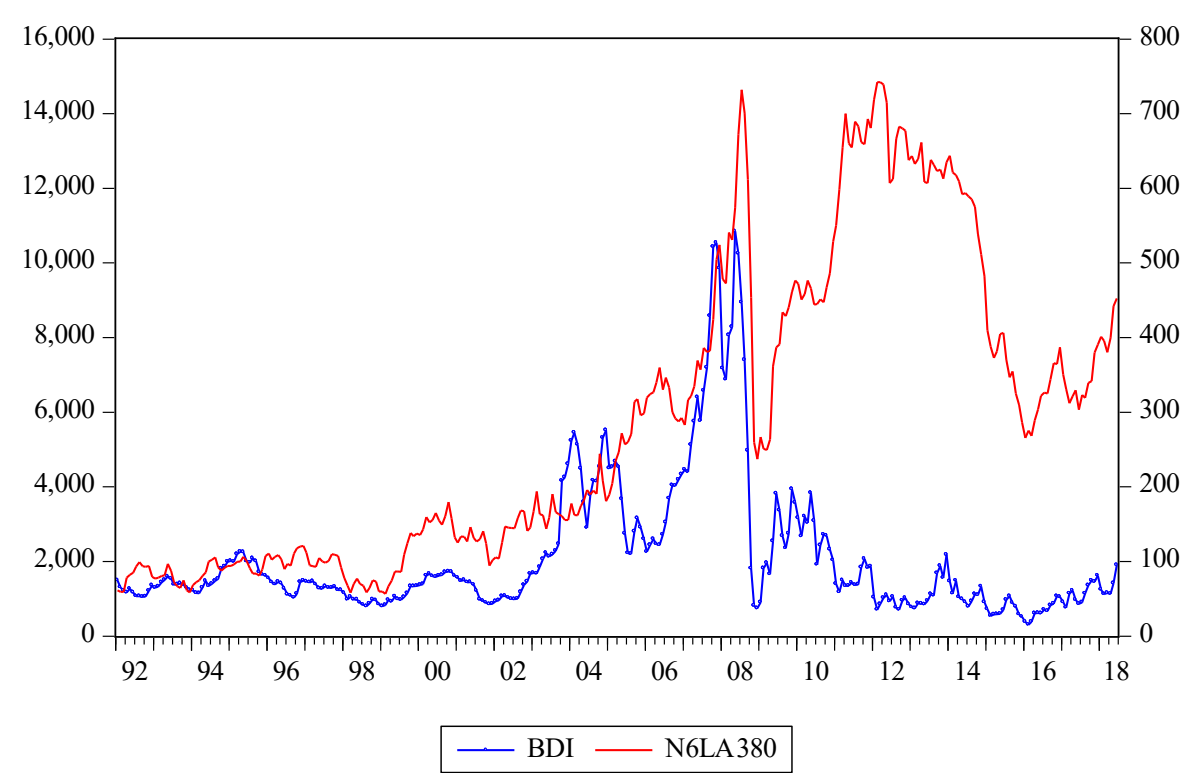

Figure 1. Graphical Display of the Variables

Descriptive statistics are provided to identify the dataset used in the study. These values are the monthly averages of the daily data for both varaibles. Because the changes in the data on this market are more prone on a monthly basis and the analysis can be carried out more practically in this frequency. The Bunker variable is the price index derived from the Bloomberg data platform. The BDI has seen 10,000 values during periods when the maritime market is bouyant, while it has fallen to 300 values during collapse periods. This can be considered as an indication of how risky and volatile the maritime market is.

Table 1. Descriptive Statistics of the Variables

\begin{tabular}{|c|c|c|}
\hline & BDI & N6LA380 \\
\hline Mean & 2083.575 & 286.2621 \\
\hline Median & 1414.659 & 240.8240 \\
\hline Maximum & 10843.65 & 742.4091 \\
\hline Minimum & 306.9048 & 56.45000 \\
\hline Std. Dev. & 1839.796 & 201.6882 \\
\hline Skewness & 2.521055 & 0.697125 \\
\hline Kurtosis & 9.944274 & 2.224727 \\
\hline Jarque-Bera & 975.8069 & 33.72103 \\
\hline Probability & 0.000000 & 0.000000 \\
\hline Observations & 318 & 318 \\
\hline
\end{tabular}

Source: Bloomberg, 2018

There is no obligation for the series to be stationary in time varying causality test in contrast to standard causality tests since time varying one is a test derived from TodaYamamoto causality test. But in this method the maximum difference (dmax) value is necessary. It indicates what is the highest integration degree of any series to become stationary. Augmented Dickey-Fuller (ADF) and Philips Perron (PP) tests are applied to determine whether the series contain unit roots and the results are presented in Table 2. 
According to the ADF test results, the integration degrees of BDI and Bunker variables are respectively I (0) and I (1). According to the PP test, the integration degrees of both variables are I (1).

Table 2. Augmented Dickey Fuller and Philips-Perron Unit Root Test Results

\begin{tabular}{|l|l|c|c|c|c|}
\hline \multirow{1}{*}{ Test } & & \multicolumn{2}{c|}{ Level } & \multicolumn{2}{c|}{ First Difference } \\
\hline \multirow{2}{*}{$\begin{array}{l}\text { Augmented } \\
\text { Dickey-Fuller }\end{array}$} & BDI & Intercept & $\begin{array}{c}\text { Trend and } \\
\text { Intercept }\end{array}$ & Intercept & $\begin{array}{c}\text { Trend and } \\
\text { Intercept }\end{array}$ \\
\cline { 2 - 6 } & Bunker & $-3.28^{* *}$ & $-3.28^{*}$ & $-12.20^{* * *}$ & $-12.18^{* * *}$ \\
\hline \multirow{2}{*}{ Philips-Perron } & BDI & -2.51 & -2.75 & $-12.54^{* * *}$ & $-12.54^{* * *}$ \\
\cline { 2 - 6 } & Bunker & -1.57 & -2.51 & $-12.33^{* * *}$ & $-12.30^{* * *}$ \\
\hline
\end{tabular}
for $1 \%$ at Trend and Intercept.

The dmax value which represents the maximum integration degree is selected as 1 in the analysis in view of these results, since the BDI is stationary at level and the Bunker is stationary when the first difference is taken. The number of bootstrap replications is selected as 1000, maksimum number of lags is selected as 12 and window for rolling regression is selected as 50. Akaike indormation crieria (AIC) is used as the information criterion in the study. Once the analysis is done in this way, the graphical representation is presented in Figure 1. The blue and wavy line shows probability values of the causality, while the orange and straight line shows the $10 \%$ critical value. It can be said that there is a causality to the freight rates from the fuel prices in the sections where the probability value is below the critical value. The detailed dates and lengths of the causalities are tabulated and presented in Table 3.

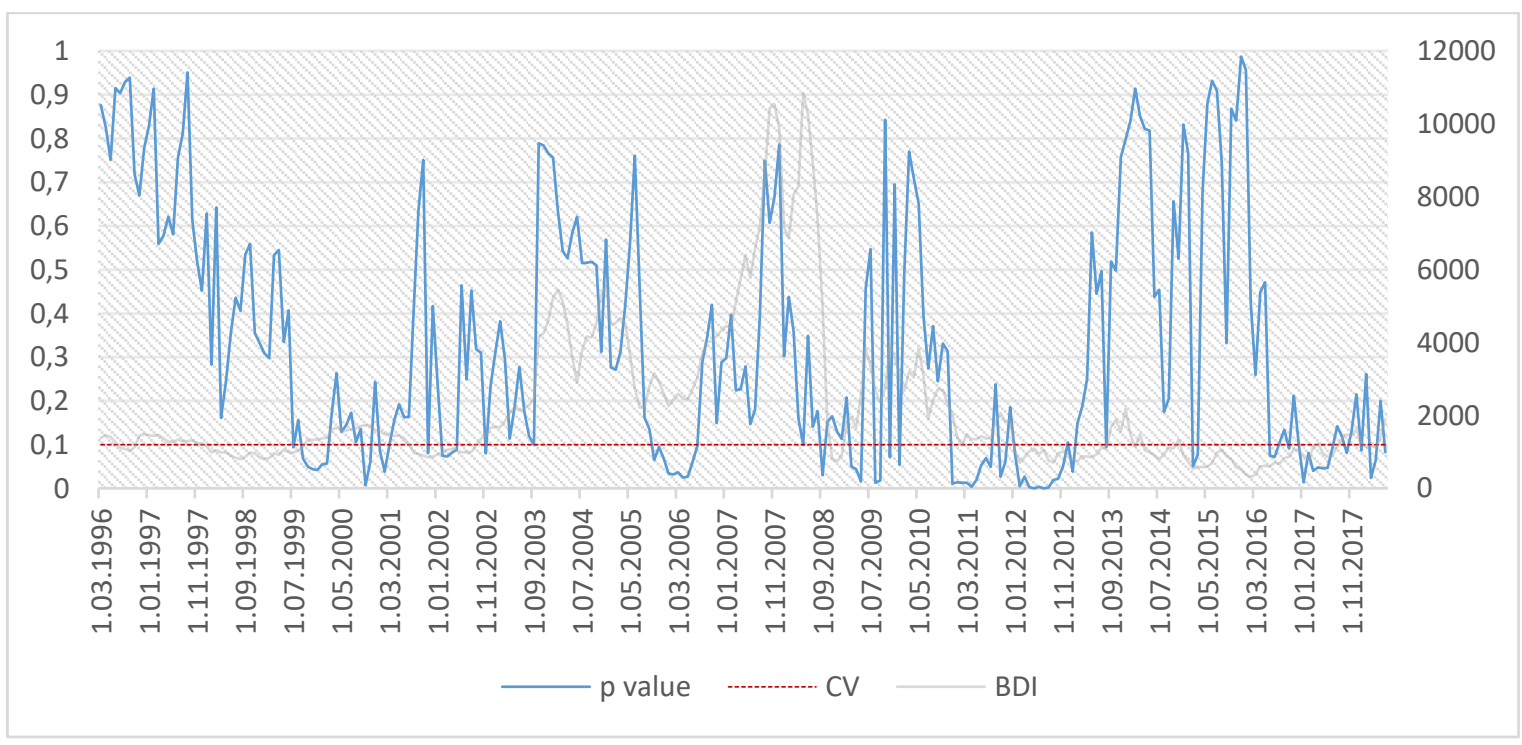

Figure 1. Time Varying Causality Results

24 causality periods with lengths ranging from 1 to 13 months in which the probability value falls below the critical value are determined. When the Table 3 is 
examined together with Figure 1, it is seen that some causality periods are interrupted by a few observations. It is more rational to examine these interrupted periods together as a single period. In this direction, the following periods may be combined into single periods; 2nd and 3rd periods; 13th, 14th and 15th periods; 22th and 23th periods. The longest period with these mergers is the 24-month period covering December 2010 and January 2013.

Figure 1 also includes a graph of the BDI variable. When it is examined together with the causality zones, it is seen that they are intersected in the declining regions of the BDI in general. Because when the recession begins on the market and freight rates begin to fall, shipowners or charterers adjust their freight rates based on their fuel costs. This cost constitutes their biggest cost item and it is virtually impossible to make a proposal under this price. However extreme freight rates are generated well above this cost level during periods when the market is alive.

Table 3. Causality Dates and Durations

\begin{tabular}{|l|c|c|c|c|c|c|c|}
\hline P. & Start & Finish & Dur. & P. & Start & Finish & Dur. \\
\hline 1 & September 99 & February 00 & 6 & 13 & December 10 & August 11 & 9 \\
\hline 2 & October 00 & November 00 & 2 & 14 & October 11 & November 11 & 2 \\
\hline 3 & January 01 & February 01 & 2 & 15 & January 12 & January 13 & 13 \\
\hline 4 & November 01 & November 01 & 1 & 16 & August 13 & August 13 & 1 \\
\hline 5 & February 02 & May 02 & 4 & 17 & February 15 & March 15 & 2 \\
\hline 6 & November 02 & November 02 & 1 & 18 & June 16 & July 16 & 2 \\
\hline 7 & October 05 & July 06 & 10 & 19 & October 16 & October 16 & 1 \\
\hline 8 & May 08 & September 08 & 5 & 20 & December 16 & July 17 & 8 \\
\hline 9 & March 09 & May 09 & 3 & 21 & October 17 & October 17 & 1 \\
\hline 10 & August 09 & September 09 & 2 & 22 & January 18 & January 18 & 1 \\
\hline 11 & November 09 & November 09 & 1 & 23 & March 18 & April 18 & 2 \\
\hline 12 & January 10 & January 10 & 1 & 24 & June 18 & June 18 & 1 \\
\hline
\end{tabular}

\section{Conclusion}

Bunker costs are one of the biggest cost items that shipowners have to meet. Naturally, they also reflect an increase in these costs in their freight price offers. Therefore, it is inevitable that there is a relationship between bunker prices and freight rates. However, extreme peak periods are observed in markets and it is not sufficient to explain the freight rates in these periods with the cost of bunker. Even in some periods, there have been so many rises in freight rates, and second-hand prices have exceeded the new construction prices. In such periods, rise in freight rates cannot be explained by the price of bunker. That is to say that the causal relationship between the freight rates and bunker prices varies according to time. In order to determine this relationship, it is thought that the most appropriate method is nonlinear time-varying causality analysis which determines the causal relationship according to the time.

There are few studies (Poulakidas and Joutz, 2009; Shen and Chou, 2015) on this relationship in the literature. They have studied this relationship with linear models and confirmed significant relationships between bunker price and freight rate. However, 
taking into account the periods when freight rates are affected by the rising demand and away from the effect of bunker prices will provide more effective results. In the analysis conducted in the period between January 1992 and June 2018, 24 causality periods with lengths ranging from 1 to 13 months in which the probability value falls below the critical value are determined. Afterwards, these periods are examined together with BDI and it is seen that they are intersected in the declining regions of the BDI in general. The reason for this is as previously mentioned, when the recession begins on the market and freight rates begin to fall, shipowners or charterers adjust their freight rates based on their bunker costs. They cannot survive in the market if they offer a lower freight rate than this cost. Because the dry bulk market is nearly perfect competitive, which means there are many buyers and sellers. This causes competition to be excessive. In fact, the market is so brutal that old ships with a high cost of operation become unable to do business as they can offer higher freight rates than new ships and are removed from the market.

At this point, it is thought that this study contributes to the current literature and practice by examining the change of freight rate-bunker price relationship over time. One limitation of the study is that the sub-indices that make up the BDI variable are not sufficiently utilized. At this point, further studies can examine this relationship using those variables. It is also thought that the examination of this relationship in the tanker and container markets will have interesting results.

\section{References}

Bal, D. P., \& Rath, B. N. (2015). "Nonlinear causality between crude oil price and exchange rate: A comparative study of China and India", Energy Economics, Vol.51, 149-156.

Balcilar, M., \& Ozdemir, Z. A. (2013a). "Asymmetric and time-varying causality between inflation and inflation uncertainty in G-7 countries", Scottish Journal of Political Economy, Vol.60, No.1, 1-42.

Balcilar, M., \& Ozdemir, Z. A. (2013b). "The export-output growth nexus in Japan: a bootstrap rolling window approach”, Empirical Economics, Vol.44, No.2, 639660 .

Bampinas, G., \& Panagiotidis, T. (2015). "On the relationship between oil and gold before and after financial crisis: Linear, nonlinear and time-varying causality testing", Studies in Nonlinear Dynamics \& Econometrics, Vol.19. No.5, 657-668.

Beenstock, M., \& Vergottis, A . R. (1989). "An econometric model of the world tanker market”, Journal of Transport Economics and Policy, Vol.23, No.2, 263- 280.

Beenstock, M., \& Vergottis, A. (1993). Econometric Modelling of World Shipping, Springer Science \& Business Media. 
Bildirici, M. E., \& Turkmen, C. (2015). "Nonlinear causality between oil and precious metals", Resources Policy, Vol.46, 202-211.

Bloomberg (2018). Baltic Dry Index, Bunker Price Index, Accessed: 15.08.2018

Clarksons Research. (2016). Market Report, https://clarksonsresearch.wordpress.com/, Accessed: 15.08.2018

El-Masry, A. A., M. Olugbode, \& J. Pointon..(2010). “The exposure of shipping firms' stock returns to financial risks and oil prices: A global perspective", Maritime Policy \& Management, Vol.37, No.5, 453-473.

Grammenos, C. T., \& Arkoulis, A. G. (2002). "Macroeconomic factors and international shipping stock returns", International Journal of Maritime Economics, Vol.4, No.1, 81-99.

Granger, C. W. (1969). "Investigating causal relations by econometric models and cross-spectral methods", Econometrica: Journal of the Econometric Society, 424438.

IMO. (2015). "Overview. As of November 20, 2015, the IMO Listed on Its Website." https://business.un.org/en/entities/13.

Inglesi-Lotz, R., Balcilar, M., \& Gupta, R. (2014). "Time-varying causality between research output and economic growth in US", Scientometrics, Vol.100, No.1, 203216.

Jugović, A., Komadina, N., \& Perić Hadžić, A. (2015). "Factors influencing the formation of freight rates on maritime shipping markets", Pomorstvo, Vol.29, No.1, 23-29.

Kavussanos, M. G., and I. D. Visvikis. (2006). "Shipping freight derivatives: A survey of recent evidence”, Maritime Policy \& Management, Vol.33, No.3, 233-255.

Li Zhan. (2017). "Review of international oil prices in 2016 and prospects for 2017," J. Contemporary Petroleum \& Petrochemical, Vol.25, No.1, 7-12.

Li, X. L., Balcilar, M., Gupta, R., \& Chang, T. (2016). “The causal relationship between economic policy uncertainty and stock returns in China and India: evidence from a bootstrap rolling window approach", Emerging Markets Finance and Trade, Vol.52, No.3, 674-689.

Notteboom, T. E., \& B. Vernimmen. (2009). "The effect of high fuel costs on liner service configuration in container shipping", Journal of Transport Geography, No.17, No.5, 325-337.

Poulakidas, A., \& Joutz, F. (2009). "Exploring the link between oil prices and tanker rates", Maritime Policy \& Management, Vol.36, No.3, 215-233. 
Review of Maritime Transport. (2017). United Nations Conference on Trade and Development, New York and Geneva.

Shen, C. W. \& Chou, C. C. (2015, August). "Temporal causality between dry bulk freight and crude oil price", Paper presented at the International Association of Maritime Economists (IAME) conference, Kuala Lumpur, Malaysia

Shi, W., \& K. X. Li. (2017). "Themes and tools of maritime transport research during 2000-2014.” Maritime Policy \& Management, Vol.44, No.2, 151-169.

Stopford, M. 2009. Maritime Economics (3rd ed), London: Routledge.

Strandenes, S. P. (1984). "Price determination in the time charter and second hand markets", Center for Applied Research, Norwegian School of Economics and Business Administration, Working Paper MU, 6

Sun, X., Liu, H., Zheng, S., \& Chen, S. (2018). "Combination hedging strategies for crude oil and dry bulk freight rates on the impacts of dynamic cross-market interaction", Maritime Policy \& Management, Vol.45, No.2, 174-196.

Yao, H.X. (2017). "The impact of oil price fluctuation on the global economy", J. National Circulation Economy, Vol.15, 90-92.

Yin, J., M. Luo, \& L. Fan. (2017). "Dynamics and interactions between spot and forward freights in the dry bulk shipping market", Maritime Policy \& Management, Vol.44, No.2, 271-288.

Zannetos, Z. S. (1966). The Theory of Oil Tankship Rates, Massachusetts Institute of Technology. 